\title{
Pioglitazone could induce remission in major depression: a meta-analysis
}

\author{
This article was published in the following Dove Press journal: \\ Neuropsychiatric Disease and Treatment \\ 19 December 2016 \\ Number of times this article has been viewed
}

\author{
Romain Colle ${ }^{1, *}$ \\ Delphine de Larminat ${ }^{1, *}$ \\ Samuel Rotenberg' \\ Franz Hozer' \\ Patrick Hardy' \\ Céline Verstuyft ${ }^{2}$ \\ Bruno Fève ${ }^{3, *}$ \\ Emmanuelle Corruble ${ }^{1, *}$ \\ 'Psychiatry Department, Hôpital \\ Bicêtre, INSERM, UMR SII78, \\ University Paris-Sud, Assistance \\ Publique-Hôpitaux de Paris, Le Kremlin \\ Bicêtre, France; ${ }^{2}$ Molecular Genetic, \\ Pharmacogenetics and Hormonology \\ Department, Hôpital Bicêtre, INSERM \\ UMR_SII84, Centre IMVA, University \\ Paris-Sud, Assistance Publique- \\ Hôpitaux de Paris, Le Kremlin Bicêtre, \\ France; ${ }^{3}$ Endocrinology Department, \\ INSERM UMR_S938, Hôpital Saint- \\ Antoine, Centre de Recherche \\ Saint-Antoine, Institut Hospitalo- \\ Universitaire ICAN, Sorbonne \\ Universités, Université Pierre et \\ Marie Curie, Assistance Publique des \\ Hôpitaux de Paris, Paris, France \\ *These authors contributed equally \\ to this work
}

Background: Pioglitazone, a selective agonist of the nuclear transcription factor peroxisome proliferator-activated receptor-gamma (PPAR- $\gamma$ ), prescribed for the treatment of type 2 diabetes, could have antidepressant properties. However, its potential to induce remission of major depressive episodes, the optimal clinical target for an antidepressant drug, is a matter of concern. Indeed, only one out of four double-blind randomized controlled trials show higher remission rates with pioglitazone than with control treatments. Hence, the main aim of this study was to perform a meta-analysis of the efficacy of pioglitazone for the treatment of MDE, focusing on remission rates.

Methods: Four double-blind randomized controlled trials, comprising 161 patients with an MDE, were included in this meta-analysis. Pioglitazone was studied either alone (one study) or as add-on therapy to conventional treatments (antidepressant drugs or lithium salts). It was compared either to placebo (three studies) or to metformin (one study). Remission was defined by a Hamilton Depression Rating Scale score $<8$ after treatment.

Results: Pioglitazone could induce higher remission rates than control treatments ( $27 \%$ versus $10 \%, I^{2}=17.3 \%$, fixed-effect model: odds ratio [OR] $=3.3,95 \%$ confidence interval [ $95 \% \mathrm{CI} ; 1.4$; 7.8], $P=0.008)$. The OR was even higher in the subgroup of patients with major depressive disorder ( $\mathrm{n}=80 ; 23 \%$ versus $8 \%, I^{2}=0.0 \%$; fixed-effect model: OR $=5.9,95 \%$ CI $[1.6 ; 22.4]$, $P=0.009)$ and in the subgroup of patients without metabolic comorbidities ( $\mathrm{n}=84 ; 33 \%$ versus $10 \%, I^{2}=0.0 \%$; fixed-effect model: $\mathrm{OR}=5.1,95 \%$ CI $[1.5 ; 17.9], P=0.01$ ). As compared to control treatments, results suggest six patients would need to be treated with pioglitazone in order to achieve the possibility of one more remission.

Conclusion: Pioglitazone, either alone or as add-on therapy to conventional treatments, could induce remission of MDE, suggesting that drugs with PPAR- $\gamma$ agonist properties may be true and clinically relevant antidepressants, even in patients without metabolic comorbidities.

Keywords: pioglitazone, major depressive episode, major depressive disorder, bipolar disorder, remission, meta-analysis

\section{Introduction}

Major depressive episodes are a severe public health problem, with a major impact on morbidity and mortality. ${ }^{1,2}$ However, the efficacy of conventional antidepressant drugs in the treatment of MDE is low, both in major depressive disorder (MDD) and in bipolar disorder (BD)., Approximately half of adults with an MDD do not achieve sustained remission despite successive adequate conventional antidepressant drug trials. ${ }^{3}$ Indeed, remission, which refers to the absence of depressive symptoms after treatment, is the main clinical target of antidepressant drug treatments. ${ }^{5-7}$ Accordingly, a true and clinically relevant antidepressant drug should be able to induce remission in depressed patients.
Correspondence: Romain Colle Psychiatry Department, Hôpital Bicêtre, INSERM, UMR SI I78, University ParisSud, Assistance Publique-Hôpitaux de Paris, 78 Rue du Général Leclerc, 94275 Le Kremlin Bicêtre, France

Tel +33 | 452 I 2524

Email romaincolle@hotmail.com 
Selective agonists of the nuclear transcription factor peroxisome proliferator-activated receptor-gamma (PPAR- $\gamma$ ), also named thiazolidinediones or glitazones, ${ }^{8}$ have anti-inflammatory and insulin-sensitizing properties ${ }^{9}$ and are widely used to treat type 2 diabetes mellitus. ${ }^{10}$ The most prescribed PPAR- $\gamma$ agonist is pioglitazone. Interestingly, in a context of high comorbidity between MDD and both metabolic syndrome and type 2 diabetes mellitus, ${ }^{10}$ preclinical studies show that PPAR- $\gamma$ agonists have antidepressant properties. Indeed, the PPAR- $\gamma$ agonist NP031115 induces antidepressantlike effects in mice. ${ }^{11}$ Rosiglitazone, another PPAR- $\gamma$ agonist, has an antidepressant-like activity in mice and rats in the tail suspension test and the forced swimming test. ${ }^{12}$ Moreover, the antidepressant effects of pioglitazone in the forced swimming test are reversed by the PPAR- $\gamma$ antagonist GW-9962.13

The first clinical use of pioglitazone in MDE was published in a case report in 2009. ${ }^{14} \mathrm{~A}$ marked improvement in depression was evidenced in a 55-year-old woman treated with pioglitazone $(30 \mathrm{mg} / \mathrm{d}$ for 12 weeks) for a metabolic syndrome and a resistant MDE. Two open-label studies ${ }^{15,16}$ published between 2012 and 2014 reported an improvement in depression with remission rates $>20 \%$ in the depressed patients treated with pioglitazone. Four double-blind randomized controlled trials (RCTs) studying the antidepressant efficacy of pioglitazone for the treatment of MDE were published between 2012 and 2015. ${ }^{17-20}$ They are summarized in Table 1. Whereas three of them ${ }^{17-19}$ reported higher depression score improvements with pioglitazone than with control treatments, only one ${ }^{17}$ out of four double-blind RCTs reported higher remission rates with pioglitazone than with placebo; the three other doubleblind RCTs ${ }^{18-20}$ failed to show any significant difference in remission rates between pioglitazone and comparators. These negative results about remission being potentially due to a lack of power related to small sample sizes, we performed a meta-analysis of the available double-blind

Table I Description and results of the four double-blind RCTs

\begin{tabular}{|c|c|c|c|c|c|c|c|c|}
\hline & \multicolumn{2}{|c|}{ Sepanjnia et al ${ }^{17}$} & \multicolumn{2}{|c|}{ Kashani et al ${ }^{18}$} & \multicolumn{2}{|c|}{ Zeinoddini et al $^{19}$} & \multicolumn{2}{|c|}{ Lin et al $2015^{20}$} \\
\hline Trial registration number & \multicolumn{2}{|c|}{ NCT0II09030 } & \multicolumn{2}{|c|}{ IRCT20II0608I556N23 } & \multicolumn{2}{|c|}{ IRCT20I2II2III556N46 } & \multicolumn{2}{|c|}{ NCT0I559857 } \\
\hline Sponsor & \multicolumn{2}{|c|}{$\begin{array}{l}\text { Tehran University of } \\
\text { Medical Sciences }\end{array}$} & \multicolumn{2}{|c|}{$\begin{array}{c}\text { Tehran University of Medical } \\
\text { Sciences }\end{array}$} & \multicolumn{2}{|c|}{$\begin{array}{l}\text { Tehran University of } \\
\text { Medical Sciences }\end{array}$} & \multicolumn{2}{|c|}{$\begin{array}{c}\text { National Institutes of } \\
\text { Health }\end{array}$} \\
\hline Drugs & Pioglitazone & Placebo & Pioglitazone & Metformin & Pioglitazone & Placebo & Pioglitazon & Placebo \\
\hline Drug dose $(\mathrm{mg} / \mathrm{d})$ & Fixed: 30 & N/A & $\begin{array}{c}\text { Fixed } \\
\text { First week: I5 } \\
\text { After: } 30\end{array}$ & $\begin{array}{c}\text { Fixed } \\
\text { First week: } 500 \\
\text { Second week: } 1,000 \\
\text { After: } 1,500\end{array}$ & $\begin{array}{c}\text { Fixed } \\
\text { First week: } \\
\text { After: } 30\end{array}$ & N/A & Fixed: 30 & N/A \\
\hline Number of patients included & \multicolumn{2}{|c|}{40} & \multicolumn{2}{|r|}{50} & \multicolumn{2}{|c|}{48} & \multicolumn{2}{|c|}{42} \\
\hline Diagnosis & \multicolumn{2}{|c|}{ MDE-MDD } & \multicolumn{2}{|c|}{ MDE-MDD } & \multicolumn{2}{|c|}{ MDE-BD } & \multicolumn{2}{|c|}{ MDE-MDD or BD } \\
\hline Age, years (mean $\pm S D)$ & \multicolumn{2}{|c|}{$32.1 \pm 5.4$} & \multicolumn{2}{|c|}{$20.8 \pm 4.0$} & \multicolumn{2}{|c|}{$32.7 \pm 4.7$} & \multicolumn{2}{|c|}{$46.4 \pm 13.8$} \\
\hline Women (\%) & \multicolumn{2}{|c|}{72.5} & \multicolumn{2}{|c|}{100} & \multicolumn{2}{|c|}{34.1} & \multicolumn{2}{|c|}{ na } \\
\hline Metabolic comorbidities & \multicolumn{2}{|c|}{ No } & \multicolumn{2}{|c|}{ Polycystic ovary syndrome: $100 \%$} & \multicolumn{2}{|c|}{ No } & \multicolumn{2}{|c|}{ Insulin resistance: $54 \%$} \\
\hline Drug, dose (mg/d) & \multicolumn{2}{|c|}{ Citalopram (30) } & & No & $\begin{array}{r}\text { Lithium sal } \\
0.6-0.8\end{array}$ & $\begin{array}{l}\text { (serum: } \\
\text { Eq/L) }\end{array}$ & $\begin{array}{r}\text { Stable t } \\
\text { with } \mathrm{m} \\
\text { antidep } \\
\text { least } 8 \text { we } \\
\text { incl }\end{array}$ & $\begin{array}{l}\text { tment } \\
\text { keted } \\
\text { sant at } \\
\text { s before } \\
\text { on }\end{array}$ \\
\hline Duration (weeks) & 6 & & & 6 & 6 & & & \\
\hline Dropout rate $(\%)$ & 0 & 0 & 20 & 20 & 8.3 & 8.3 & 9.5 & 14.2 \\
\hline Number of patients analyzed & 4 & & & 40 & 4 & & & \\
\hline Depression scale & $\mathrm{HD}$ & & & ADRS & $\mathrm{HD}$ & & & \\
\hline Baseline score (mean $\pm S D)$ & 25.4 & & & $.1 \pm 1.8$ & $23.1=$ & & 15. & \\
\hline Baseline score (mean $\pm S D)$ & $25.6 \pm 3.7$ & $25.1 \pm 3.2$ & $14.6 \pm 1.8$ & $15.6 \pm \mathrm{I} .6$ & $23.0 \pm 1.7$ & $23.2 \pm 1.8$ & $17.2 \pm 5.6$ & $14.0 \pm 4.1$ \\
\hline Score change (mean \pm SD) & $16.7 \pm 3.5$ & $13.4 \pm 3.5$ & $5.6 \pm 2.1$ & $1.3 \pm 0.9$ & $14.0 \pm 3.2$ & $11.7 \pm 2.3$ & $4.1 \pm$ na & $3.2 \pm$ na \\
\hline Remission rates, $\mathrm{n}(\%)$ & $9(45 \%)$ & $3(15 \%)$ & $4(20 \%)$ & $0(0 \%)$ & $5(23 \%)$ & I (4\%) & na & na \\
\hline Major adverse events (yes/no) & No & No & No & No & No & No & na & na \\
\hline $\begin{array}{l}\text { Adverse events (difference } \\
\text { between groups) }\end{array}$ & No diff & rence & $\begin{array}{l}\text { Increased } \\
\text { appetite }\end{array}$ & $\begin{array}{l}\text { Decreased } \\
\text { appetite }\end{array}$ & No diffe & ence & na & na \\
\hline
\end{tabular}

Notes: Remission: HDRS score $<8$. Bold values show $P<0.05$ when remission rates were compared between pioglitazone and placebo.

Abbreviations: RCTs, randomized controlled trials; MDE, major depressive episode; MDD, major depressive disorder; BD, bipolar disorder; SD, standard deviation; na, not available; N/A, not applicable; HDRS, Hamilton Depression Rating Scale. 
RCTs of pioglitazone for the treatment of MDE, focusing specifically on remission rates.

\section{Methods}

\section{Data sources}

A search was conducted by two investigators (DDL and RC) on PubMed, Cochrane Central Register of Controlled Trials, ClinicalTrials.gov, and EU Clinical Trials Register with the following keywords: (pioglitazone) OR (thiazolidinedione) OR (PPAR- $\gamma$ ) [Title/Abstract] AND (depress*) [Title/Abstract] OR (bipolar) [Title/Abstract]. The search period comprised between January 1990 and August 2016. The study selection process is shown in Figure 1.

Briefly, to be selected, studies had to fulfill the following criteria:

1. Double-blind RCT with PPAR- $\gamma$ agonists

2. Standardized diagnostic criteria for MDE (DSM-IV) in patients with MDD or BD (depressions due to general medical conditions were not included because of a different clinical presentation, etiopathogeny and response to treatments)

3. Assessment of depression at baseline and follow-up using standardized depression rating scales.

The selection of studies was carried out by two independent investigators (RC and DDL; Cohen's kappa =1).

Based on these criteria, four double-blind RCTs of pioglitazone were included for the qualitative analysis and the meta-analysis (Table 1). Indeed, to the best of our knowledge, there was no published RCT examining the potential of other glitazones to induce remission of MDE.

\section{Data extraction}

The following data were recorded from each study: sponsor, name of the study, registration trial number, design, number of patients included, dropout rates, number of patients analyzed, mean age, percentage of women, diagnosis

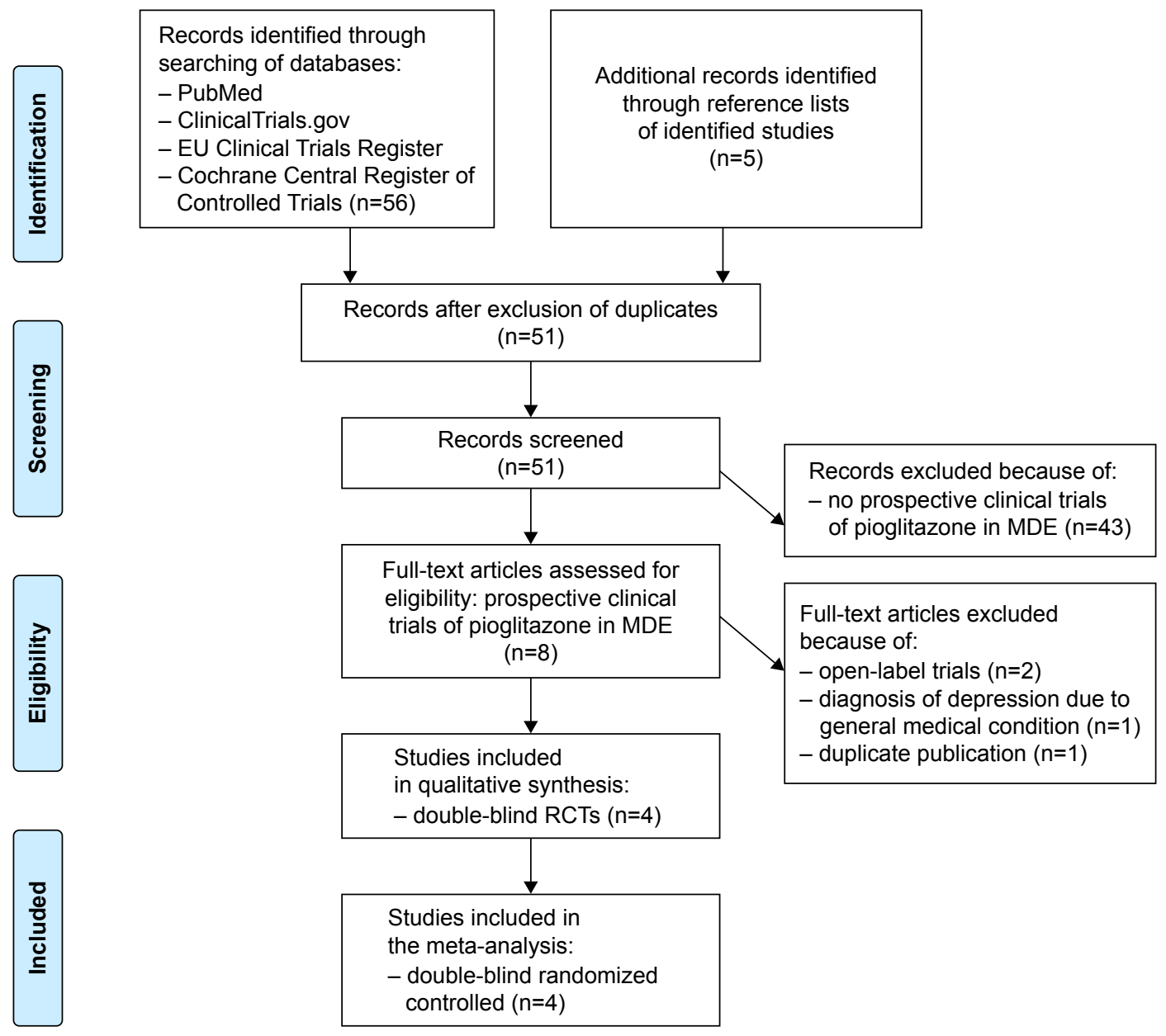

Figure I Flow diagram of selection process for studies.

Abbreviations: MDE, major depressive episode; RCTs, randomized controlled trials. 
criteria of MDE, drug, dosage and duration of treatment, concomitant use of psychotropic drugs, and standardized depression rating scale used to assess depression at baseline and follow-up (ie, Hamilton Depression Rating Scale [HDRS]; Table 1). ${ }^{21}$

\section{Quality assessment}

The risks of biases, ie, selection bias (random sequence generation and allocation concealment), performance bias (blinding of participants and personnel), detection bias (blinding of outcome assessment), attrition bias (incomplete outcome data addressed), and reporting bias (selective reporting), were assessed for each study according to the Cochrane Handbook. ${ }^{22}$

The overall quality of evidence was assessed according to the Grading of Recommendations Assessment, Development and Evaluation (GRADE) approach ${ }^{23,24}$ based on several factors: study design, study quality, consistency, directness, and reporting bias. Four levels of quality of evidence were defined according to the GRADE system (Table 2). ${ }^{24}$

The publication biases were assessed by extensive search of unpublished data in the clinical trial register (funnel plot or Egger's tests were not performed due to the limited number of included studies). A GRADE profile was fulfilled for each study and for each outcome of the meta-analysis. Cochrane risk of biases and GRADE quality of evidence for each study are reported in Table 2 .

Three studies had a low risk of bias and a high quality of evidence, and one study ${ }^{20}$ had a serious risk of bias and a low level of evidence (Table 2). The quality of evidence for the meta-analyzed outcomes was downgraded by the limited number of studies, the limited number of patients included in each study, and the analysis of the subgroup of completers, leading to a moderate quality of evidence for the meta-analysis.

Regarding publication bias, all the included studies were registered on appropriate websites, there was no major change between the registered protocol and the published study and no unpublished completed trial was found.

\section{Statistical analysis}

This meta-analysis was performed following the Preferred Reporting Items for Systematic Reviews and MetaAnalyses (PRISMA) group guidelines. ${ }^{25}$ It was performed using R 2.15.3 and the meta and r-meta packages. All tests were two tailed, and the statistical significance threshold was $P=0.05$. Our primary criterion was the remission rate. Remission was defined by an HDRS score $<8$. $^{5-7}$ Our secondary assessment criterion was the HDRS score improvement from baseline to endpoint. Meta-analyses were performed in the whole sample and, in case of positive results, in the subgroup of patients with MDD and in the subgroup of patients without metabolic comorbidities. The $I^{2}$ test reflecting the percentage of total variation across studies was calculated to assess heterogeneity of studies. ${ }^{26}$ The choice of the statistical methods was done following the position developed by Rothman and Greenland. ${ }^{27}$ Fixed-effect models were used as main models. But, random-effect models were also computed because, in the presence of heterogeneity, a random-effect model weighs the studies relatively more equally than a fixed-effect model; however, it is less conservative. ${ }^{22}$ The two models were reported. Regarding remission, odds ratios (ORs) and their 95\% confidence intervals (CI) comparing pioglitazone and control treatments were

Table 2 Cochrane risk of biases and GRADE quality of evidence for each study

\begin{tabular}{|c|c|c|c|c|}
\hline & $\begin{array}{l}\text { Sepanjnia et } \mathrm{al}^{17} \\
(2012)\end{array}$ & $\begin{array}{l}\text { Kashani et } \mathrm{al}^{18} \\
(2013)\end{array}$ & $\begin{array}{l}\text { Zeinoddini et } \text { al }^{19} \\
(2015)\end{array}$ & $\begin{array}{l}\text { Lin et } \mathrm{al}^{20} \\
(2015)\end{array}$ \\
\hline \multicolumn{5}{|l|}{ Risks of biases (Cochrane) } \\
\hline Random sequence generation & Low & Low & Low & Low \\
\hline Allocation concealment & Low & Low & Low & Low \\
\hline Blinding of participants and personnel & Low & Low & Low & Low \\
\hline Blinding of outcome assessment & Low & Low & Low & Low \\
\hline Incomplete outcome data addressed & Low & Low & Unclear & Serious \\
\hline Selective reporting & Low & Low & Low & Serious \\
\hline \multicolumn{5}{|l|}{ Quality of evidence (GRADE) } \\
\hline Study design & High & High & High & High \\
\hline Study quality & High & High & High & Low \\
\hline Consistency & High & High & High & Low \\
\hline Directness & High & Moderate & High & High \\
\hline Reporting bias & Low & Low & Low & Serious \\
\hline GRADE level of evidence & High & High & High & Low \\
\hline
\end{tabular}

Abbreviation: GRADE, Grading of Recommendations Assessment, Development and Evaluation. 
computed. Regarding HDRS score improvements, mean differences between pioglitazone and control treatments were computed. Since there was no report of standard deviation (SD) values for remission rates and HDRS score improvements in the study of Lin et $\mathrm{al}^{20}$ and because this study had a high risk of bias and a low level of evidence, two different strategies were used and reported to cope with this issue. 1) To avoid a bias due to the exclusion of this study, SD values and remission rates were imputed using a conservative approach: the highest SD values of the other studies (ie, SD values of the two groups of the study of Sepanjnia et $\mathrm{al}^{17}$ ) were imputed for both the pioglitazone (3.5) and the control (3.5) treatment groups. An equal number of four remitters, which was in line with the HDRS improvement in this study, were imputed for both treatment groups. 2) We computed the meta-analysis while excluding the study of Lin et al. ${ }^{20}$ Finally, to quantify the effect size, the number needed to treat (NNT) to achieve remission was calculated from the following formula: $\mathrm{NNT}=1 /($ remission rate with pioglitazone - remission rate with control treatment). ${ }^{28}$

\section{Results}

Four double-blind RCTs ${ }^{17-20}$ were analyzed, comprising 161 patients with a diagnosis of MDE (MDD or BD; Table 2). A total of 81 patients were treated with pioglitazone. In all, 80 patients received a control treatment, of which, 60 patients received a placebo ${ }^{17,19,20}$ and 20 patients received metformin. ${ }^{18}$ In the four studies included, the primary outcome was the HDRS score improvement, remission being a secondary outcome.

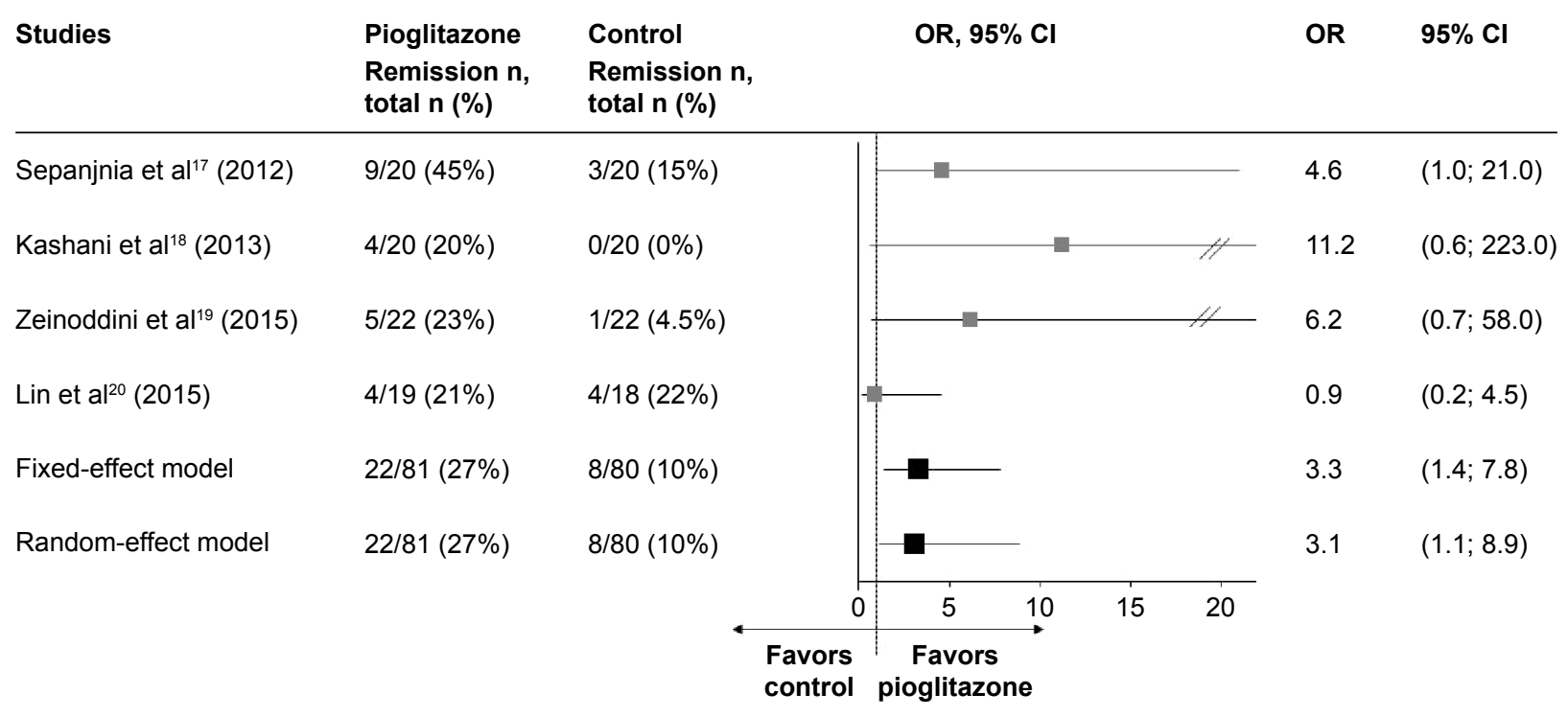

\section{Remission}

In the whole sample (Figure 2), pioglitazone induced higher remission rates than control treatments $(27 \%$ versus $10 \%$; low heterogeneity: $P^{2}=17.3 \%, Q=3.6, P=0.30$; fixed-effect model: $\mathrm{OR}=3.3,95 \%$ CI $[1.4 ; 7.8], z=2.6, P=0.008$; random-effect model: $\mathrm{OR}=3.1,95 \% \mathrm{CI}[1.1 ; 8.9], z=2.1, P=0.03)$. The NNT was six patients to have one more remission with pioglitazone than with control treatments. Even after excluding the study of Lin et al, ${ }^{20}$ pioglitazone induced higher remission rates than control treatments (29\% versus $6 \%$; low heterogeneity: $I^{2}=0.0 \%, Q=0.3, P=0.87$; fixed-effect model: $\mathrm{OR}=6.0$, 95\% CI $[1.9 ; 18.8], z=3.1, P=0.002$; random-effect model: $\mathrm{OR}=5.7,95 \%$ CI $[1.8 ; 18.1], z=2.9, P=0.003)$.

In the subgroup of patients with MDD $(n=80)$, pioglitazone induced higher remission rates than control treatments ( $23 \%$ versus $8 \%$; low heterogeneity: $P^{2}=0.0 \%, Q=0.3, P=0.60$; fixed-effect model: $\mathrm{OR}=5.9,95 \%$ CI $[1.6 ; 22.4], z=2.6$, $P=0.009$; random-effect model: $\mathrm{OR}=5.5,95 \% \mathrm{CI}[1.4 ; 21.4]$, $z=2.5, P=0.01)$.

In the subgroup of patients without metabolic comorbidities $(n=84)$, pioglitazone induced higher remission rates than control treatments (33\% versus 10\%; low heterogeneity: $I^{2}=0.0 \%, Q=0.0, P=0.83$; fixed-effect model: $\mathrm{OR}=5.1,95 \%$ CI $[1.5 ; 17.9], z=2.6, P=0.01$; random-effect model: $\mathrm{OR}=5.1$, $95 \%$ CI $[1.4 ; 17.7], z=2.5, P=0.01)$.

Since inclusion criteria differ between studies (unremitted depression with HDRS $\geq 7,{ }^{20}$ mild-to-moderate depression with HDRS $<20,{ }^{18}$ and moderate-to-severe depression with HDRS $\geq 22^{17}$ or HDRS $>20^{19}$ ), the severity of depression at baseline differs between studies (Table 1). Thus,

igure 2 Meta-analysis of remission rates in the whole sample. Abbreviations: $\mathrm{OR}$, odds ratio; $\mathrm{Cl}$, confidence interval. 
a meta-regression analysis was performed for HDRS score at baseline, showing no impact of this variable on remission rates $(P=0.87)$.

Since the type of concurrent prescribed medication (Table 1) differs between studies (no comedication in one study, ${ }^{18}$ antidepressants in two studies ${ }^{17,20}$ and lithium salts comedication in one study ${ }^{19}$ ), a meta-regression analysis was performed for comedication, showing no impact of this variable on remission rates (no comedication versus antidepressant comedication: $P=0.44$; no comedication versus lithium comedication: $P=0.77$; antidepressant comedication versus lithium comedication: $P=0.58$ ). Furthermore, since pioglitazone is metabolized by the CYP3A4 and is a modest inhibitor of this enzyme, a drug-drug interaction could explain the treatment effect in the two studies ${ }^{18,20}$ with comedications metabolized by the CYP3A4. However, the meta-regression analysis shows no impact of comedication metabolized by the CYP3A4 on remission rates $(P=0.25)$.

\section{HDRS score improvement}

In the whole sample, pioglitazone induced higher HDRS score improvement than control treatments (high heterogeneity: $I^{2}=71.3 \%, Q=10.4, P=0.02$; fixed-effect model: mean difference $=3.3,95 \%$ CI $[2.6 ; 4.0], z=9.1, P<0.0001$; randomeffect model: mean difference $=2.8,95 \%$ CI $[1.4 ; 4.3], z=3.8$, $P=0.0001)$. Even after excluding the study of Lin et al, pioglitazone induced higher HDRS score improvement than control treatments (high heterogeneity: $I^{2}=65.2 \%, Q=5.6$, $P=0.06$; fixed-effect model: mean difference $=3.5,95 \% \mathrm{CI}$ [2.8; 4.3], $z=9.3, P<0.0001$; random-effect model: mean difference $=3.4,95 \%$ CI $[2.0 ; 4.7], z=4.8, P<0.0001)$.

In the subgroup of patients with MDD $(n=80)$, pioglitazone induced higher HDRS score improvement than control treatments (low heterogeneity: $I^{2}=0.0 \%, Q=0.7$, $P=0.41$; fixed-effect model: mean difference $=4.1$, $95 \%$ CI $[3.2 ; 5.0], z=8.9, P<0.0001 ;$ random-effect model: mean difference $=4.1,95 \%$ CI $[3.2 ; 5.0], z=8.9, P<0.0001)$.

In the subgroup of patients without metabolic comorbidities $(n=84)$, pioglitazone induced higher HDRS score improvement than control treatments (low heterogeneity: $I^{2}=0.0 \%, Q=0.6, P=0.43$; fixed-effect model: mean difference $=2.6,95 \%$ CI $[1.4 ; 3.7], z=4.5, P<0.0001$; randomeffect model: mean difference $=2.6,95 \%$ CI $[1.4 ; 3.7]$, $z=4.5, P<0.0001)$.

\section{Discussion}

Pioglitazone, either alone or as add-on therapy, could induce remission of major depressive episodes. The remission rate is threefold higher with pioglitazone than with control treatments (placebo in three studies and metformin in one study). Interestingly, this result is seen in depressed patients with MDD and in patients without metabolic comorbidities and is independent of depression severity at baseline and comedication. Based on the four published RCTs, of which only one was positive, this meta-analysis is the first one arguing for the relevance of pioglitazone to obtain remission of MDE.

Nevertheless, some limits have to be emphasized. There were only four studies identified that met the criteria: each of these had a small sample size and was heterogeneous with regard to diagnosis criteria of mood disorder (MDD or BD), sex ratio, age, severity at baseline, concomitant psychotropic treatments, control treatments, and duration of follow-up. In particular, one of the included studies had a serious risk of bias and a low quality of evidence. However, the exclusion of this study did not change the results of this meta-analysis, and both fixed-effect and random-effect models report significant results. However, the clinical relevance of this result may be low since the mean HDRS difference is $<4$. Since the study doses were fixed at $30 \mathrm{mg} / \mathrm{d}$, there are no dose-response data available. A dose-response effect would have been useful to show that the clinical outcomes observed are genuinely pharmacological. Moreover, the usefulness of pioglitazone in severe cases of depression remains unclear. Since the four RCTs were short term (6-12 weeks), the conclusions of this meta-analysis do not apply to long-term remission, whereas depression is a long-term disorder and treatment course. This begs the question of how long pioglitazone should be continued as an add-on and whether its clinical effects are maintained. In this meta-analysis, we did analyze neither response rates, which were available in only two studies, ${ }^{17,19}$ nor the subgroup of patients with metabolic comorbidities, because the results were not reported separately in each study. It has also to be acknowledged that it cannot be concluded from our results that pioglitazone alone could induce remission, since it was used as add-on therapy in three out of four RCTs. Indeed, from a therapeutic standpoint, the most promising result comes from the work of Sepanjnia et $\mathrm{al}^{17}$ and is consistent with the idea that PIO might enhance the beneficial effects of selective serotonin reuptake inhibitors. Importantly, pioglitazone is the only drug assessed in the four RCTs. Thus, we cannot know whether its positive effects on remission rates are due to its PPAR- $\gamma$ agonist properties or due to other mechanisms of action of this drug. However, preclinical data $^{11-13}$ and open-label studies ${ }^{15,29}$ are coherent with our results and argue for their generalizability to the class of PPAR- $\gamma$ agonists. The antidepressant effects of pioglitazone 
may be mediated by its effects on systemic metabolism and/or inflammation. In line with this hypothesis, MDD is associated with both metabolic syndromes ${ }^{30-34}$ and neuroimmune system abnormalities. ${ }^{35}$ Several studies have shown an association between antidepressant effects and improvement in insulin resistance ${ }^{15,18}$ or inflammation markers such as IL-6. ${ }^{15,16}$ In addition, neuroprotective effects of PPAR- $\gamma$ agonists have been shown in a variety of preclinical models. ${ }^{36-39}$ Recent data show that serotonin leads to activation of PPAR- $\gamma$ responsive genes and enhances lipid accumulation in fat cells. ${ }^{40-42}$ Part of the antidepressant efficacy of conventional antidepressants may thus involve the activity of the PPAR- $\gamma$ pathway.

Nonetheless, based on the previous limitations, this meta-analysis is unlikely to provide definitive answers to the use of pioglitazone as either an add-on to standard medications or a stand-alone treatment. Two other RCTs of pioglitazone are currently ongoing to assess pioglitazone for the treatment of bipolar depression, alone (NCT01717040, ClinicalTrials.gov) and as add-on therapy (2014-003803-31, clinicaltrialsregisters.ue). In these two ongoing registered double-blind RCTs, several biomarkers of insulin resistance and inflammation, BDNF levels and cognitive functioning will be assessed. These studies will enable to assess in larger samples the benefits of pioglitazone for MDE and to explore its mechanisms of action in patients with mood disorders.

\section{Conclusion}

In patients with MDE, pioglitazone, either alone or as add-on therapy to conventional treatments, could induce remission, suggesting that drugs with PPAR- $\gamma$ agonist properties may be true and clinically relevant antidepressants, even in patients without metabolic comorbidities. Even if the use of pioglitazone in type II diabetes is declining due to its adverse effects, further studies are needed to explore the potential of drugs with PPAR- $\gamma$ agonist properties to induce remission in major depression.

\section{Acknowledgment}

The authors thank Magda Rosinska for linguistic revision.

\section{Disclosure}

Romain Colle, Delphine de Larminat, Samuel Rotenberg, Franz Hozer, Patrick Hardy, Céline Verstuyft, and Emmanuelle Corruble report no conflicts of interest in this work. Bruno Fève has received conference fees from AstraZeneca, Sanofi, Novo Nordisk and MSD, consulting fees from Sanofi, and grants from ViiV Healthcare, Janssen, and MSD. The authors report no other conflicts of interest in this work.

\section{References}

1. Kupfer DJ, Frank E, Phillips ML. Major depressive disorder: new clinical, neurobiological, and treatment perspectives. Lancet. 2012; 379(9820):1045-1055.

2. Global Burden of Disease Study 2013 Collaborators. Global, regional, and national incidence, prevalence, and years lived with disability for 301 acute and chronic diseases and injuries in 188 countries, 1990-2013: a systematic analysis for the Global Burden of Disease Study 2013. Lancet. 2015;386(9995):743-800.

3. McIntyre RS, Filteau MJ, Martin L, et al. Treatment-resistant depression: definitions, review of the evidence, and algorithmic approach. $J$ Affect Disord. 2014;156:1-7.

4. Perlis RH, Ostacher MJ, Patel JK, et al. Predictors of recurrence in bipolar disorder: primary outcomes from the Systematic Treatment Enhancement Program for Bipolar Disorder (STEP-BD). Am J Psychiatry. 2006; 163(2):217-224.

5. Frank E, Prien RF, Jarrett RB, et al. Conceptualization and rationale for consensus definitions of terms in major depressive disorder. Remission, recovery, relapse, and recurrence. Arch Gen Psychiatry. 1991; 48(9):851-855.

6. Rush AJ, Kraemer HC, Sackeim HA, et al. Report by the ACNP Task Force on response and remission in major depressive disorder. Neuropsychopharmacology. 2006;31(9):1841-1853.

7. Moller HJ. Outcomes in major depressive disorder: the evolving concept of remission and its implications for treatment. World J Biol Psychiatry. 2008;9(2):102-114.

8. Consoli A, Formoso G. Do thiazolidinediones still have a role in treatment of type 2 diabetes mellitus? Diabetes Obes Metab. 2013;15(11): 967-977.

9. Kapadia R, Yi JH, Vemuganti R. Mechanisms of anti-inflammatory and neuroprotective actions of PPAR-gamma agonists. Front Biosci. 2008; 13:1813-1826.

10. Lincoff AM, Tardif JC, Schwartz GG, et al. Effect of aleglitazar on cardiovascular outcomes after acute coronary syndrome in patients with type 2 diabetes mellitus: the AleCardio randomized clinical trial. JAMA. 2014;311(15):1515-1525.

11. Rosa AO, Kaster MP, Binfare RW, et al. Antidepressant-like effect of the novel thiadiazolidinone NP031115 in mice. Prog Neuropsychopharmacol Biol Psychiatry. 2008;32(6):1549-1556.

12. Eissa Ahmed AA, Al-Rasheed NM, Al-Rasheed NM. Antidepressantlike effects of rosiglitazone, a PPARgamma agonist, in the rat forced swim and mouse tail suspension tests. Behav Pharmacol. 2009;20(7): 635-642.

13. Sadaghiani MS, Javadi-PaydarM, Gharedaghi MH, Fard YY, Dehpour AR. Antidepressant-like effect of pioglitazone in the forced swimming test in mice: the role of PPAR-gamma receptor and nitric oxide pathway. Behav Brain Res. 2011;224(2):336-343.

14. Kemp DE, Ismail-Beigi F, Calabrese JR. Antidepressant response associated with pioglitazone: support for an overlapping pathophysiology between major depression and metabolic syndrome. Am J Psychiatry. 2009;166(5):619.

15. Kemp DE, Ismail-Beigi F, Ganocy SJ, et al. Use of insulin sensitizers for the treatment of major depressive disorder: a pilot study of pioglitazone for major depression accompanied by abdominal obesity. $J$ Affect Disord. 2012;136(3):1164-1173.

16. Kemp DE, Schinagle M, Gao K, et al. PPAR-gamma agonism as a modulator of mood: proof-of-concept for pioglitazone in bipolar depression. CNS Drugs. 2014;28(6):571-581.

17. Sepanjnia K, Modabbernia A, Ashrafi M, Modabbernia MJ, Akhondzadeh S. Pioglitazone adjunctive therapy for moderate-to-severe major depressive disorder: randomized double-blind placebo-controlled trial. Neuropsychopharmacology. 2012;37(9):2093-2100.

18. Kashani L, Omidvar T, Farazmand B, et al. Does pioglitazone improve depression through insulin-sensitization? Results of a randomized double-blind metformin-controlled trial in patients with polycystic ovarian syndrome and comorbid depression. Psychoneuroendocrinology. 2013;38(6):767-776. 
19. Zeinoddini A, Sorayani M, Hassanzadeh E, et al. Pioglitazone adjunctive therapy for depressive episode of bipolar disorder: a randomized, double-blind, placebo-controlled trial. Depress Anxiety. 2015;32(3): $167-173$.

20. Lin KW, Wroolie TE, Robakis T, Rasgon NL. Adjuvant pioglitazone for unremitted depression: clinical correlates of treatment response. Psychiatry Res. 2015;230(3):846-852.

21. Hamilton M. A rating scale for depression. J Neurol Neurosurg Psychiatry. 1960;23:56-62.

22. Higgins JPT, Green S (editors). Cochrane Handbook for Systematic Reviews of Interventions Version 5.1.0 [updated March 2011]. Chap 8. The Cochrane Collaboration, 2011. Available from: www.handbook. cochrane.org

23. Atkins D, Best D, Briss PA, et al. Grading quality of evidence and strength of recommendations. BMJ. 2004;328(7454):1490.

24. Guyatt GH, Oxman AD, Vist GE, et al. GRADE: an emerging consensus on rating quality of evidence and strength of recommendations. $B M J$. 2008;336(7650):924-926.

25. Moher D, Liberati A, Tetzlaff J, Altman DG, Group P. Preferred reporting items for systematic reviews and meta-analyses: the PRISMA statement. PLoS Med. 2009;6(7):e1000097.

26. Higgins JP, Thompson SG. Quantifying heterogeneity in a metaanalysis. Stat Med. 2002;21(11):1539-1558.

27. Rothman KJ, Greenland S. Modern Epidemiology. 2nd ed. Philadelphia: Lippincott Williams \& Wilkins; 1998.

28. Kraemer HC, Kupfer DJ. Size of treatment effects and their importance to clinical research and practice. Biol Psychiatry. 2006;59(11):990-996.

29. Rasgon NL, Kenna HA, Williams KE, Powers B, Wroolie T, Schatzberg AF. Rosiglitazone add-on in treatment of depressed patients with insulin resistance: a pilot study. Scientific WorldJournal. 2010;10: 321-328.

30. Rhee SJ, Kim EY, Kim SH, et al. Subjective depressive symptoms and metabolic syndrome among the general population. Prog Neuropsychopharmacol Biol Psychiatry. 2014;54:223-230.

31. Corruble E, El Asmar K, Trabado S, et al. Treating major depressive episodes with antidepressants can induce or worsen metabolic syndrome: results of the METADAP cohort. World Psychiatry. 2015; 14(3):366-367.
32. Pan A, Keum N, Okereke OI, et al. Bidirectional association between depression and metabolic syndrome: a systematic review and metaanalysis of epidemiological studies. Diabetes Care. 2012;35(5): 1171-1180.

33. Vancampfort D, Correll CU, Wampers M, et al. Metabolic syndrome and metabolic abnormalities in patients with major depressive disorder: a meta-analysis of prevalences and moderating variables. Psychol Med. 2014;44(10):2017-2028.

34. Mezuk B, Eaton WW, Albrecht S, Golden SH. Depression and type 2 diabetes over the lifespan: a meta-analysis. Diabetes Care. 2008;31(12): 2383-2390.

35. Hodes GE, Kana V, Menard C, Merad M, Russo SJ. Neuroimmune mechanisms of depression. Nat Neurosci. 2015;18(10):1386-1393.

36. Chen YC, Wu JS, Tsai HD, et al. Peroxisome proliferator-activated receptor gamma (PPAR-gamma) and neurodegenerative disorders. Mol Neurobiol. 2012;46(1):114-124.

37. Moreno S, Farioli-Vecchioli S, Ceru MP. Immunolocalization of peroxisome proliferator-activated receptors and retinoid $\mathrm{X}$ receptors in the adult rat CNS. Neuroscience. 2004;123(1):131-145.

38. Skerrett R, Pellegrino MP, Casali BT, Taraboanta L, Landreth GE. Combined liver X receptor/peroxisome proliferator-activated receptor gamma agonist treatment reduces amyloid beta levels and improves behavior in amyloid precursor protein/presenilin 1 mice. J Biol Chem. 2015;290(35):21591-21602.

39. Lecca D, Nevin DK, Mulas G, et al. Neuroprotective and anti-inflammatory properties of a novel non-thiazolidinedione PPARgamma agonist in vitro and in MPTP-treated mice. Neuroscience. 2015;302:23-35.

40. Kinoshita M, Ono K, Horie T, et al. Regulation of adipocyte differentiation by activation of serotonin (5-HT) receptors 5-HT2AR and 5-HT2CR and involvement of microRNA-448-mediated repression of KLF5. Mol Endocrinol. 2010;24(10):1978-1987.

41. Gres S, Gomez-Zorita S, Gomez-Ruiz A, Carpene C. 5-hydroxytryptamine actions in adipocytes: involvement of monoamine oxidase-dependent oxidation and subsequent PPARgamma activation. J Neural Transm (Vienna). 2013;120(6):919-926.

42. Young $\mathrm{KC}$, Bai $\mathrm{CH}, \mathrm{Su} \mathrm{HC}$, et al. Fluoxetine a novel anti-hepatitis $\mathrm{C}$ virus agent via ROS-, JNK-, and PPARbeta/gamma-dependent pathways. Antiviral Res. 2014;110:158-167.
Neuropsychiatric Disease and Treatment

\section{Publish your work in this journal}

Neuropsychiatric Disease and Treatment is an international, peerreviewed journal of clinical therapeutics and pharmacology focusing on concise rapid reporting of clinical or pre-clinical studies on a range of neuropsychiatric and neurological disorders. This journal is indexed on PubMed Central, the 'PsycINFO' database and CAS,

\section{Dovepress}

and is the official journal of The International Neuropsychiatric Association (INA). The manuscript management system is completely online and includes a very quick and fair peer-review system, which is all easy to use. Visit http://www.dovepress.com/testimonials.php to read real quotes from published authors. 